\title{
Longitudinal Evaluation of Sealing Molars with and without Incipient Dental Caries in a Public Health Program
}

\author{
Keith E. Heller, DDS, MPH; Susan G. Reed, DDS, MPH; Fred W. Bruner, DDS; Stephen A. Eklund, DDS, \\ MHSA, DrPH; Brian A. Burt, BDS, MPH, PhD
}

\begin{abstract}
Objectives: This study undertook a retrospective evaluation of the effect of sealants on the caries experience of initially sound and incipient permanent first molar pit and fissure surfaces. Methods: Records of children with complete five-year records were obtained from a school-based dental sealant program in a fluoridated community. Sealants were placed on 677 tooth surfaces in 96 children; 120 tooth surfaces in 17 children who received baseline examinations were not sealed because of lack of caregiver consent. Tooth surfaces were initially diagnosed as being sound or having incipient lesions, and evaluated for caries status after five years. Results: For initially incipient surfaces the five-year decay rate was 10.8 percent ( 41 of 380 surfaces) for sealed surfaces and 51.8 percent (29 of 56 surfaces) for nonsealed surfaces with an odds ratio of $8.88(95 \% \mathrm{Cl}=4.56$, 17.35). Initially sound surfaces had a decay rate of 8.1 percent (24 of 297 surfaces) for sealed surfaces and 12.5 percent ( 8 of 64 surfaces) for nonsealed surfaces with an odds ratio of $1.63(95 \% \mathrm{Cl}=0.63,4.08)$. The two odds ratios were significantly different. Conclusions: Initially sound tooth surfaces were unlikely to become decayed in five years, and did not benefit greatly from the application of sealants. Within the limitations of this study, there were clear efficiencies in sealing incipient, but not sound, surfaces. The targeting of teeth with incipient caries for sealants is therefore recommended. [J Public Health Dent 1995;55(3):148-53]
\end{abstract}

Key Words: pit and fissure sealants, incipient caries, dental caries.

Sealants of various types have been in use for over 25 years to prevent pit and fissure dental caries $(1,2)$, and there is ample evidence of their longterm efficacy (3). With an eye to cost effectiveness, public health interest has come to focus on selective sealing of incipient lesions, rather than the sealing of large numbers of sound surfaces (4-8). Viable bacterial counts in the carious lesion decrease after successful sealant application (9-11), and little, if any, progression of the carious lesion has been detected as long as the sealant remains intact (12-19). These findings led the National Institute of Dental Research in the mid-1980s to advocate sealant use on incipient lesions (20).

Other research, however, has reported radiographic evidence of caries under intact sealants of teeth origi- nally diagnosed as clinically sound (21-23). In these studies, the researchers have hypothesized that caries progression could result from microorganisms surviving in the tooth by obtaining nutrients from the pulp via the dentinal tubules. This research involved teeth with no clinical evidence of caries ("hidden caries"), which, the authors emphasized, may function differently from teeth that have clinically detectable signs of incipient caries such as staining or deep and sticky fissures. Because of differences in presealant caries diagnostic criteria, different presealant caries status, and different periods of observation, it is difficult to compare these results for teeth with sealants and caries progression underneath with those reporting little or no caries progression under intact sealants. While this issue merits fur- ther study, the evidence to date suggests that incipient lesions can be safely sealed.

This paper evaluates a school-based sealant program conducted since 1987 by the Mott Children's Health Center (MCHC), a private nonprofit corporation that serves the Flint and Beecher school districts in Genessee County, Michigan. The MCHC goal is to provide a caries prevention program in this fluoridated area that will benefit school-aged children with poor access to clinic-based dental services. The focus of this evaluation was to compare the outcomes of sealing sound tooth surfaces and surfaces with incipient carious lesions.

\section{Methods}

Conduct of the MCHC Sealant Program. Eight elementary schools in the Flint school district were originally invited to participate in this program. Schools with high numbers of children participating in the schools' free lunch programs were selected. A letter describing dental sealants and the school sealant program, along with a consent form, were sent home with children at the participating schools. All students were required to have a signed consent form in order to obtain the dental sealants.

All children, whether or not they were participating in the sealant program, were examined by the dentist at the initial and subsequent yearly examinations. Since these examinations were considered to be an oral health status screening, the school board and MCHC determined that no written consent was necessary for the child to be examined. For this evaluation, the children who did not obtain sealants because of lack of consent served as a comparison group to those children

The authors are affiliated with the Program in Dental Public Health, School of Public Health, University of Michigan, Ann Arbor, MI 48109-2029. Internet: kheller@umich.edu. Send correspondence and reprint requests to Dr. Heller. This study was supported by National Research Service Award \#DE07157 from the National Institute of Dental Research. Manuscript received: $6 / 1 / 94$; returned to authors for revision: $7 / 20 / 94$; accepted for publication: $11 / 18 / 94$. 
who did receive sealants.

A dentist, dental hygienist, and dental assistant visited each school once a year during the five years of the program. The same dentist and hygienist have participated in the program since its inception. All children present at the school at the time of the dental team visit were examined by the dentist. Examinations were conducted at the school with the child reclining in a portable dental chair using a Star M-G2 cowhorn explorer, mouth mirror, and a dental lamp. No radiographs were taken.

Only permanent first molars were examined and sealed. All permanent first molar pit and fissure surfaces were initially evaluated by the dentist. Surfaces were rated as "sound" if there were no visible defects or discolorations of the enamel surface and the explorer did not stick or catch upon probing. An "incipient" rating was given to a surface if it had dark staining, a chalky appearance, or if the explorer had slight sticking upon probing, but there were no apparent enamel surface defects visible. Surfaces diagnosed as "frank caries" demonstrated definite softness or sticking upon probing with a visually apparent defect of the enamel surface.

Two different surfaces of each maxillary and mandibular molar were examined in this survey, for a maximum of eight examined first molar surfaces per child. The two maxillary molar surfaces examined were the mesial-occlusal (occlusal pits and fissures mesial to the oblique ridge) and the distal occlusal-lingual (occlusal pits and fissures distal to the oblique ridge and the lingual groove). The two mandibular molar surfaces examined were the occlusal (occlusal pits and fissures) and the buccal (buccal pit).

For children with signed consents, all erupted surfaces diagnosed as sound or with incipient caries and having no frank caries, prior restorations, or prior sealants were sealed. Teeth were cleaned with pumice, acid etched for 30 seconds, and then sealed by the hygienist using an opaque sealant (Delton(8) and cured with a visible light curing unit for 30 seconds per surface.

All children were examined by the dentist at subsequent yearly school dental visits using the previously described criteria. Any partially sealed surfaces were resealed by the dental

TABLE 1

Comparison of All Initially Examined Children and Children Who Met Inclusion Criteria

\begin{tabular}{|c|c|c|c|}
\hline Number of & $\begin{array}{l}\text { All Initially } \\
\text { Examined Children }\end{array}$ & $\begin{array}{l}\text { Children Meeting } \\
\text { Inclusion Criteria }\end{array}$ & $P$-value \\
\hline Children & 557 & 113 & \\
\hline Children $w /$ prior sealants & $18(3.2)$ & $5(4.4)$ & $.57^{*}$ \\
\hline $\begin{array}{l}\text { Children w/ initial frank } \\
\text { caries }\end{array}$ & $33(5.9)$ & $6(5.3)$ & $.80+$ \\
\hline $\begin{array}{l}\text { Children } w / \text { initial } \\
\text { restorations }\end{array}$ & $25(4.5)$ & $5(4.4)$ & $.98+$ \\
\hline $\begin{array}{l}\text { Children } w / \text { consent for } \\
\text { sealant application }\end{array}$ & $373(67.0)$ & $96(85.0)$ & $.00+$ \\
\hline Surfaces & 4,456 & 904 & \\
\hline Erupted surfaces & $3,490(77.6)$ & $843(93.4)$ & $.00 t$ \\
\hline $\begin{array}{l}\text { Surfaces } w / \text { initial frank } \\
\text { caries } \ddagger\end{array}$ & $61(1.7)$ & $14(1.7)$ & $.86 t$ \\
\hline $\begin{array}{l}\text { Surfaces } w / \text { initial } \\
\text { restorations } \neq\end{array}$ & 49 (1.4) & $18(2.1)$ & $.12+$ \\
\hline Surfaces w/ prior sealants $\ddagger$ & $70(2.0)$ & $13(1.5)$ & $.38 t$ \\
\hline Initial sound surfacesł & $1,458(41.8)$ & $361(42.8)$ & $.58+$ \\
\hline Initial incipient surfacesł & $1,852(53.0)$ & $437(51.8)$ & $.52 t$ \\
\hline
\end{tabular}

Numbers in parentheses are percents.

*Fisher two-tailed test.

tChi-square test.

$\ddagger$ Denominator is number of erupted surfaces.

hygienist. The examining dentist was not responsible for, nor involved with, the future dental treatment of the children. There was only one dentist who screened the children throughout the five years. No duplicate examinations for examiner's consistency were carried out.

Evaluation Methods. MCHC made their records of the sealant program available for analysis. Because the most appropriate evaluation was considered to be the five-year outcome of the sealants, only children who were seen in the first grade in the 1987-88 school year and then reexamined in the 1992-93 school year were included in this study. Since the Beecher elementary schools only went up to the fifth grade, none of these children were followed for the five-year time period; therefore, these schools were not included in this evaluation. The other inclusion criterion for this analysis was that when in the first grade the child had at least one erupted, nonrestored and nonsealed permanent first molar pit or fissured surface without frank caries. Surfaces that were not sealed in the first grade because they were not yet erupted, but were subsequently sealed, were not included in this analysis.

Data were analyzed using Epi Info (24) and SAS (25). Odds ratios and either chi-square or two-tailed Fisher exact statistics were used for categorical data analyses. Woolf's test for heterogeneity of odds ratios was used for stratified analyses. Logistic regression was used for multivariate analyses. Generalized Estimating Equation (GEE) procedures were utilized to control for cluster effects (26).

\section{Results}

Description of Comparison Groups. A total of 557 first grade students were initially seen in the 1987-88 school year in the Flint schools. Of these children, 113 (20 percent) met the inclusion criteria described above. Of the 444 excluded children, 81 were excluded because they had no eligible teeth in the first grade. The other 363 children. were excluded because of lack of five-year follow-up.

Comparisons of the initially examined students and the 113 children who met the inclusion rules are shown 
TABLE 2

Comparisons of Dental Status of Sealed and Nonsealed Groups

\begin{tabular}{|c|c|c|c|}
\hline Number of & Sealed Group & Nonsealed Group & $P$-value \\
\hline Children & 96 & 17 & \\
\hline Children $w /$ prior sealants & $3(3.1)$ & $2(11.8)$ & $.16^{*}$ \\
\hline $\begin{array}{l}\text { Children w/ initial frank } \\
\text { caries }\end{array}$ & $5(5.2)$ & $1(5.9)$ & $1.00^{*}$ \\
\hline $\begin{array}{l}\text { Children } w / \text { initial } \\
\text { restorations }\end{array}$ & $5(5.2)$ & $0(0.0)$ & $1.00^{*}$ \\
\hline Surfaces & 768 & 136 & \\
\hline Erupted surfaces & $713(92.8)$ & $130(95.6)$ & $.24+$ \\
\hline $\begin{array}{l}\text { Surfaces w/ initial frank } \\
\text { caries } \ddagger\end{array}$ & $8(1.1)$ & $6(4.6)$ & $.01^{*}$ \\
\hline $\begin{array}{l}\text { Surfaces } w / \text { initial } \\
\text { restorations } \neq\end{array}$ & $18(2.5)$ & $0(0.0)$ & $.09^{*}$ \\
\hline Surfaces w/ initial sealants $\ddagger$ & $9(1.3)$ & $4(3.1)$ & $.13^{*}$ \\
\hline Initial sound surfacesł & $297(41.7)$ & $64(49.2)$ & $.11+$ \\
\hline Initial incipient surfacesł & $381(53.4)^{\S}$ & $56(43.1)$ & $.03+$ \\
\hline
\end{tabular}

Numbers in parentheses are percents.

*Fisher two-tailed test.

tChi-square test.

$\ddagger$ Denominator is number of erupted surfaces.

$\$ 380$ surfaces available for analysis because one surface had no follow-up data.

FIGURE 1

Distribution of Carious, Filled, and Missing Permanent First Molar Surfaces after Five Years

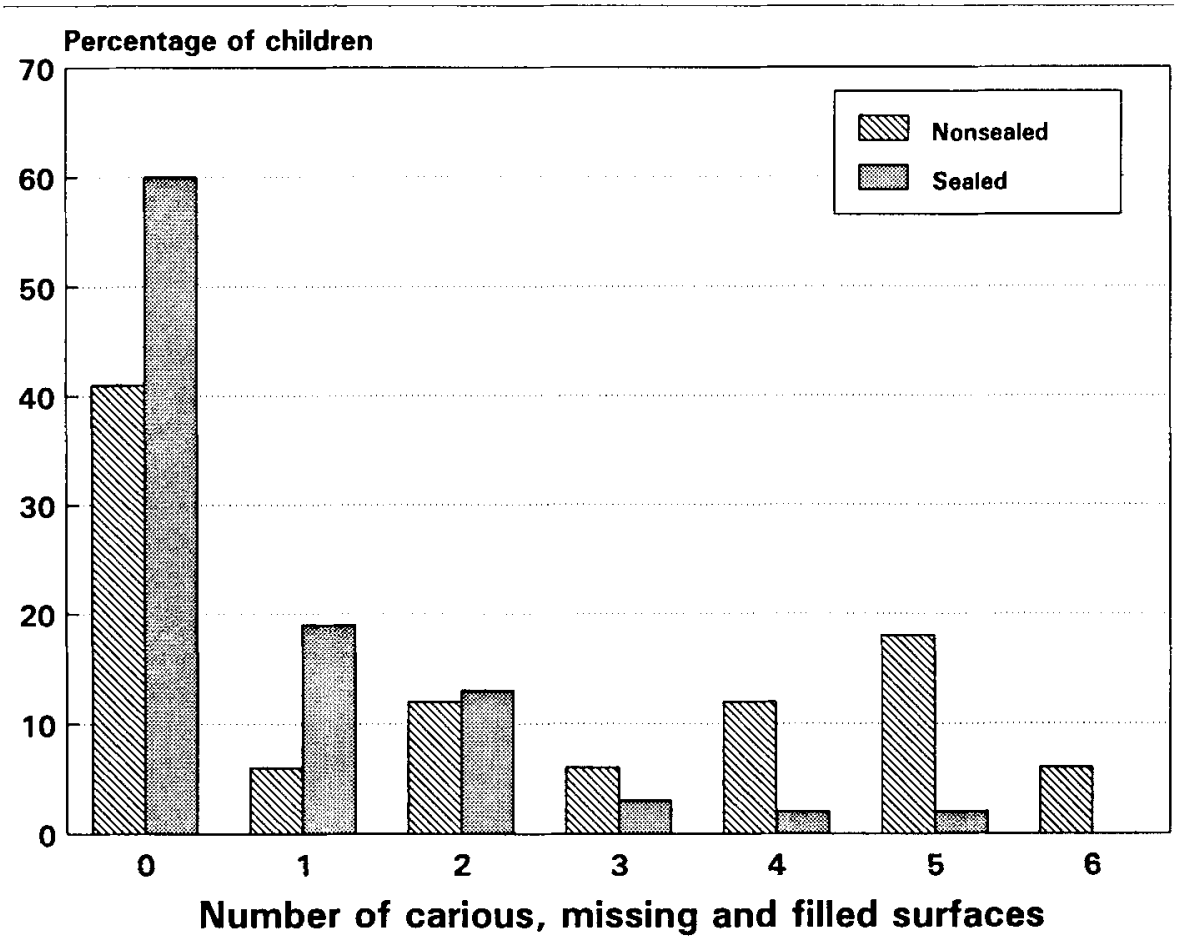

in Table 1. The two groups did not differ significantly in terms of prior first molar frank caries, restoration, or sealant experience. Of children who had caries experience (frank caries or filled teeth), the mean number of affected surfaces per child was 2.1 $(S D=1.8)$ for the full group, and 3.1
$(\mathrm{SD}=2.2)$ for the inclusion group. The two groups differed significantly in their percents of erupted surfaces. The mean number of erupted teeth per child was $6.3(\mathrm{SD}=2.9)$ for the full group and $7.1(\mathrm{SD}=1.9)$ for the inclusion group. This difference is expected because of presence of erupted teeth being part of the inclusion criteria. The two groups also differed in the percent of children who received consent. The inclusion group had a significantly higher proportion of children who received consent for sealant application than the full initial group.

Of the 113 children in the inclusion group, 96 ( 85 percent) received at least one sealant in the first grade and $17(15$ percent) did not receive sealants and served as the comparison group. Initial dental status of the sealant and nonsealant groups are compared in Table 2. The nonsealed children had a significantly higher percent of tooth surfaces with initial frank caries and a lower percent of initial incipient surfaces. For frank caries and restorations combined, the sealed and nonsealed groups were not significantly different in caries experience (two-tailed Fisher test, $P=.62$ ). The median number of teeth with initial caries experience for children with caries experience was two in the sealed group. The one child in the nonsealed group with caries experience had six affected teeth. While the vast majority of children in both groups were caries free, those with a caries history tended to have multiple lesions. The mean number of surfaces available for analysis for the nonsealed group was $7.1(\mathrm{SD}=1.9)$. For the children with sealants, the mean number of sealed surfaces was $7.1(\mathrm{SD}=2.0)$, most children having received sealants on all eight surfaces.

Caries Experience for Sealed and Nonsealed Surfaces. Figure 1 shows the distribution of children having new caries experience on their permanent first molar surfaces at the end of the five-year observation period. While 60 percent of the children with sealants developed no new frank caries and received no restorations or extractions on their permanent first molar surfaces, only 41 percent of the nonsealed children were unaffected. Approximately 7 percent of the children with sealants had three or more surfaces with caries experience, compared to 41 percent of the nonsealed children. 
A total of 797 molar surfaces in the group of 113 children were included in this analysis (Table 3 ). These surfaces had no prior restorations, sealants, or initial frank caries. Of the total 797 surfaces, 677 (84.9\%) were sealed. For sealed and nonsealed surfaces combined, 12.8 percent (102 of 797 surfaces) became carious over the five years. Of the sealed surfaces, 9.6 percent ( 65 of 677 surfaces) became carious, with 27 surfaces having frank caries and 38 surfaces having been restored. The proportion of nonsealed surfaces that became frankly carious in five years was 30.8 percent ( 37 of 120 surfaces), with 12 surfaces having frank caries, 23 surfaces having been restored, and two surfaces being extracted. For the children who had sealants, 58 percent of their caries experience was from restorations. For the nonsealed group, 68 percent of their caries experience was from restorations. This difference was not significant (chi-square, $P=.36$ ).

The odds of nonsealed tooth surfaces becoming frankly carious after five years was 4.20 times greater than for sealed surfaces $(95 \% \mathrm{CI}=2.56,6.88$; $P<.001)$. This finding indicates that sealants in this program were effective at reducing dental caries, and that there was a significant relationship between decay experience and sealant status. When stratified by tooth sur-

TABLE 3

Caries Experience for Sealed and Nonsealed Permanent First Molar Surfaces after Five Years

\begin{tabular}{|c|c|c|c|}
\hline & $\begin{array}{c}\text { No } \\
\text { Decay }\end{array}$ & DMF & Total \\
\hline Sealed & $\begin{array}{l}612 \\
(93)\end{array}$ & $\begin{array}{r}65 \\
(36)\end{array}$ & $\begin{array}{l}677 \\
(96)\end{array}$ \\
\hline Nonsealed & $\begin{array}{r}83 \\
(16)\end{array}$ & $\begin{array}{r}37 \\
(10)\end{array}$ & $\begin{array}{l}120 \\
(17)\end{array}$ \\
\hline Total & $\begin{array}{c}695 \\
(109)\end{array}$ & $\begin{array}{l}102 \\
(46)\end{array}$ & $\begin{array}{c}797 \\
(113)\end{array}$ \\
\hline
\end{tabular}

Cell values indicate the number of surfaces in that category; numbers in parentheses indicate the number of children in that category. Odds ratio $=4.20(95 \% \mathrm{CI}=2.56,6.88)$. Chisquare $=41.2, P<.001$. Decay rate of all surfaces for 5 years $=0.128$ (102 of 797 surfaces). Decay rate of sealed surfaces for 5 years $=0.096$ ( 65 of 677 surfaces). Decay rate of nonsealed surfaces for 5 years $=0.308$ ( 37 of 120 surfaces). faces, the odds ratios were 2.42 and 8.75 for the buccal and occlusal surfaces of the mandibular molars, respectively, and 3.86 and 3.88 for the mesial-occlusal and distal-occlusallingual maxillary surfaces, respectively. These four odds ratios did not significantly differ from each other using Wolfe's test of heterogeneity $(P=.25)$; thus, further analyses were not stratified by tooth surface.

Because the tooth surface data were not independent, being grouped at the patient level (multiple surfaces per patient) and at the tooth level (multiple surfaces per tooth), GEE was used to adjust for intrapatient and intratooth clustering effects. This procedure, while not affecting the odds ratio point estimates from the logistic regression coefficients, adjusts the standard errors of the coefficients to compensate for the clustering. Adjustment for clustering at the tooth level using GEE widens the 95 percent confidence interval for the odds ratio of 4.20 to 2.39 and 7.37. Adjustment for clustering at the patient level widened the confidence interval to 1.96 and 8.98. After adjusting for clustering at either level, the significant relationship between sealant status and decay experience remains.

Caries Experience for Sound and Incipient Surfaces. For all the surfaces observed at baseline, 54.7 percent ( 436

TABLE 4

Caries Experience for Sealed and Nonsealed Initially Sound Surfaces after Five Years

\begin{tabular}{|c|c|c|c|}
\hline & $\begin{array}{l}\text { No } \\
\text { Decay }\end{array}$ & DMF & Total \\
\hline Sealed & $\begin{array}{l}273 \\
(50)\end{array}$ & $\begin{array}{c}24 \\
(14)\end{array}$ & $\begin{array}{l}297 \\
(51)\end{array}$ \\
\hline Nonsealed & $\begin{array}{l}56 \\
(9)\end{array}$ & $\begin{array}{c}8 \\
(2)\end{array}$ & $\begin{array}{l}64 \\
(9)\end{array}$ \\
\hline Total & $\begin{array}{l}329 \\
(59)\end{array}$ & $\begin{array}{c}32 \\
(16)\end{array}$ & $\begin{array}{l}361 \\
(60)\end{array}$ \\
\hline
\end{tabular}

Cell values indicate the number of surfaces in that category; numbers in parentheses indicate the number of children in that category. Odds ratio $=1.63$ (95\% CI $=0.63,4.08)$. Chisquare=1.27, $P<.26$. Decay rate of all sound surfaces for 5 years $=0.089$ ( 32 of 361 surfaces). Decay rate of sound sealed surfaces for 5 years $=0.081$ (24 of 297). Decay rate of nonsealed surfaces for 5 years $=0.125$ ( 8 of 64 surfaces). of 797 surfaces) were rated as incipient according to the diagnostic criteria used. This percent was consistent across all of the different tooth surfaces and teeth. Caries experience after five years for surfaces initially rated as either sound or incipient is presented in Tables 4 and 5. For both sealed and nonsealed surfaces, surfaces with initial incipient lesions had higher levels of caries experience than sound surfaces. When sealed and nonsealed surfaces were compared, the nonsealed sound and incipient surfaces had higher rates of caries experience than the sealed surfaces. For initially sound surfaces that had caries experience, 69 percent of the caries experience consisted of restorations. For initially incipient surfaces, this proportion was 59 percent. These proportions were not significantly different (chi-square, $P=.83$ ).

Considering the number of children represented in each cell in Tables 4 and 5 , the mean caries experience per child with caries experience was 2.0 surfaces per child for the sound group and 2.2 surfaces per child for the incipient group. Along with the distribution of caries shown in Figure 1, this finding suggests that the caries is not highly concentrated in only a few individuals.

When the data for caries rates for sealed and nonsealed surfaces are

TABLE 5

Caries Experience for Sealed and Nonsealed Initially Incipient Surfaces after Five Years

\begin{tabular}{lccccc}
\hline & $\begin{array}{c}\text { No } \\
\text { Decay }\end{array}$ & & DMF & & Total \\
\cline { 5 - 6 } \cline { 5 - 6 } Sealed & 339 & & 41 & & 380 \\
& $(58)$ & & $(24)$ & & $(63)$ \\
Nonsealed & 27 & & 29 & & 56 \\
& $(7)$ & & $(8)$ & & $(8)$ \\
Total & 366 & & 70 & & 436 \\
& $(65)$ & & $(32)$ & & $(71)$
\end{tabular}

Cell values indicate the number of surfaces in that category; numbers in parentheses indicate the number of children in that category. Odds ratio $=8.88(95 \% \mathrm{CI}=4.56,17.35)$. Chisquare $=60.9, P<.001$. Decay rate of all incipient surfaces for 5 years $=0.160$ (70 of 436 surfaces). Decay rate of incipient sealed surfaces for 5 years $=0.108$ ( 41 of 380 surfaces). Decay rate of incipient nonsealed surfaces for 5 years $=0.518$ (29 of 56 surfaces). 
stratified by their initial incipient or sound status, the differences in the odds ratios are striking. Incipient surfaces had an odds ratio of 8.88 (95\% $\mathrm{CI}=4.56,17.35 ; P<.001)$, indicating that the sealant status was highly related to the caries outcome for these surfaces. Initially sound surfaces, on the other hand, had an odds ratio of 1.63 (95\% $\mathrm{CI}=0.63,4.08 ; P=.185$ ). This last odds ratio is not significantly different from the null value for the odds ratio of 1 , indicating that the sealant status was weakly related to caries outcome for sound surfaces. The two odds ratios were significantly different from each other using Woolf's test for heterogeneity $(P=.0015)$. The interaction term (sealant status $x$ incipient status) in the logistic regression model of sealant and incipient status predictors on caries outcome also was significant $(P=.0015)$. These last two statistics indicate that there was significant effect modification by incipient status. This means that the association between sealant status and caries outcome was dependent on whether the tooth surface was initially sound or incipient.

\section{Discussion}

This evaluation carried several limitations, principally because it was a post hoc process in a public health program that was not characterized by the rigor of a clinical trial. While the criteria for initial tooth surface status were described fairly precisely, it was not possible to evaluate how consistent the examiner was in applying these criteria. The fact that a single experienced examiner was used does help in minimizing this source of error. It also was not possible to evaluate the validity of the dentist's diagnoses and the effects of examiner bias in this study. The dentist commented on the difficulty in diagnosing incipient lesions, and stated that "when in doubt" he used the incipient classification. The high percent of surfaces rated as being incipient may suggest that the examiner was liberal in the use of this diagnostic category.

The absence of random allocation of the comparison groups also necessarily presents the risk of selection bias. No questions were asked of caregivers regarding demographic characteristics, prior dental history, or reasons for giving or not giving consent; therefore, comparisons of groups are limited to observed dental charac- teristics of the permanent first molars. As shown in Tables 1 and 2, there were no striking differences between the children who were included or excluded from this analysis, and between children whose caregivers gave permission for sealants and those who did not. Few children in any group had prior caries, restorations, or sealants in their permanent first molars. Most children who were excluded from the final analyses lacked five-year data. Few were excluded because of prior sealants, previous caries experience, or lack of erupted teeth.

Children received regular dental care, including dental restorations, during the five-year evaluation period. It was not possible to determine the reasons for these restorations or the caries diagnostic criteria of the practitioners who provided the treatment. Children in the sealed and nonsealed groups had similar proportions of restorations among surfaces with caries experience. Similarly, the proportions of restorations among the surfaces with caries experience for the initially sound and incipient surfaces were similar. It appears that treatment was consistent between the groups in this analysis, and that treatment bias was minimal.

The size of the comparison groups was also of concern for this evaluation. While there were 120 surfaces available for evaluation for the nonsealant group, this represented only 17 children. Such small numbers precluded doing more tooth- or surface-stratified analyses. Because of the small sample size, one necessarily must be cautious in reaching conclusions regarding these data and generalizing the results to other populations.

The results of this analysis found that these light-polymerized sealant surfaces had a decay rate that was 31.2 percent that of nonsealed surfaces after five years, indicating the overall efficiency of sealants. This finding agrees with Ripa's summary of clinical studies of autopolymerized sealants, which found the mean five-year caries levels of sealed teeth to be approximately one-third that of nonsealed teeth (3). Several studies have found the long-term success of autopolymerized sealants to be greater than that of light-polymerized sealants (27-30).

All surfaces classified as initially having incipient caries had higher decay rates than teeth judged to be in- itially sound. It is possible, however, that the examiner may have used different criteria for incipient-appearing and sound-appearing teeth, and therefore could have been more likely to rate the stained and sticky pits and fissures as being frankly carious at the follow-up examinations. On the other hand, the examiner may have been less likely to rate these surfaces as frankly carious because they had been left unfilled until that time. Because of the opaque nature of the sealants, though, the examiner would not have known the sound or incipient status of the sealed surfaces. However, it is possible that if a sealant was partially missing or totally lost, and the fissure appeared questionable with staining or sticking of the explorer, the examiner may have been biased to rate the surface as carious.

Incipient surfaces also were found to have higher odds ratios than the sound surfaces (Tables 4 and 5). This indicates that the sealants had a high effectiveness in preventing caries on these surfaces. Previous investigators have shown similar retention and success rates for sound and incipient tooth surfaces (18).

Implications for Program Planning. From these data, several findings are of interest regarding the use of sealants in caries prevention programs. It was apparent from this analysis that sealants are effective in preventing caries over a five-year period because sealed surfaces had a decay rate that was 31.2 percent of that seen in nonsealed surfaces after five years. However, 9.6 percent of the sealed surfaces were found to be carious or restored over five years, although this figure includes restorations of surfaces whose caries status at the time of the treatment is unknown to us. The status of the sealant in sealed teeth that became carious had not been recorded so it is not possible to determine if sealant loss was related to decay. In the MCHC program, attempts were made to annually check teeth and reseal them if necessary. In light of the number of sealed teeth that developed decay, this annual examination seems warranted.

This project found higher odds ratios, indicating higher sealant effectiveness, for sealed incipient surfaces. While no cost data were considered in this paper, these findings are of relevance to the cost effectiveness of 
sealants. Leverett et al. (4) found improved cost effectiveness when teeth with early signs of caries were selected for sealants; and Weintraub and Burt (7) recommended the restriction of sealants to incipient lesions to improve cost effectiveness in public programs. Other methods of targeting the most susceptible patients have been recommended. Weintraub et al. (8), in an analysis of the clinic-based sealant program at $\mathrm{MCHC}$, found higher cost effectiveness when sealants were limited to children with prior restorations in permanent first molars, which perhaps suggests that teeth with incipient lesions were those most often chosen for sealing.

While it may be efficacious to seal all pit and fissure surfaces, this approach is unlikely to be a cost effective one for a public sealant program. When resources are limited, utilizing the most efficient procedures and targeting the most susceptible and treatment-responsive patients, teeth, and tooth surfaces are necessary. Selective use of preventive and treatment procedures is accepted, and expected, in the medical community. The findings from this school-based sealant program support the concept of targeting teeth with incipient lesions to optimize the efficiency of sealants.

\section{Acknowledgments}

The authors wish to acknowledge Dr. Fred Daprai and Mary Beth Noonan, who conducted the Mott Children's Health Center school sealant program.

\section{References}

1. Cueto EI, Buonocore MG. Sealing of pits and fissures with an adhesive resin. Its use in caries prevention.J Am Dent Assoc 1967;75:121-8.

2. Simonsen RJ. Retention and effectiveness of dental sealant after 15 years. J Am Dent Assoc 1991;122:34-42.

3. Ripa LW. Sealants revisited: an update of the effectiveness of pit-and-fissure sealants. Caries Res 1993; 27(Suppl 1):77-
82.

4. Leverett DH, Handelman SL, Brenner CM, Iker HP. Use of sealants in the pre vention and early treatment of carious lesions: cost analysis. I Am Dent Assoc 1983;106:39-42.

5. American Dental Association, Council on Dental Research. Cost effectiveness of sealants in private practice and standards for use in prepaid dental care. J Am Dent Assoc 1985;110:103-7.

6. Eklund SA. Factors affecting the cost of fissure sealants: a dental insurer's perspective. J Public Health Dent 1986;46: 133-40.

7. Weintraub JA, Burt BA. Prevention of dental caries by the use of pit-and-fissure sealants. I Public Health Policy 1987;8: 542-60.

8. Weintraub JA, Stearns SA, Burt BA, Beltran E, Eklund SA. A retrospective analysis of the cost effectiveness of dental sealants in a children's health center. Soc Sci Med 1993;36:1483-93.

9. Handelman SL. Buonocore MG, Heseck DJ. A preliminary report on the effect of fissure sealant on bacteria in dental caries. J Prosthet Dent 1972;27:390-2.

10. Going RE, Loesche WJ, Grainger DA, Syed SA. The viability of microorganisms five years after covering with a fissure sealant. J Am Dent Assoc 1978;97: 455-62.

11. Mertz-Fairhurst EI, Schuster GS, Williams JE, Fairhurst CW. Clinical progress of sealed and unsealed caries. Part I: depth changes and bacterial counts. J Prosthet Dent 1979;42:521-6.

12. Mertz-Fairhurst EJ, Schuster GS, Williams JE, Fairhurst CW. Clinical progress of sealed and unsealed caries. Part II: standardized radiographs and clinical observations. J Prosthet Dent 1979;42: 663-7.

13. Jensen OE, Handelman SL. Effect of an autopolymerizing sealant on the viability of the microflora in occlusal dental caries. Scand J Dent Res 1980;88:382-8.

14. Handelman SL, Leverett DH, Solomon ES, Brenner CM. Use of adhesive sealants over occlusal carious lesions: radio graphic evaluation. Community Dent Oral Epidemiol 1981;9:256-9.

15. Handelman SL, Leverett DH, Iker HP. Longitudinal radiographic evaluation of the progress of caries under sealants. J Pedodontics 1985;9:119-26.

16. Mertz-Fairhurst EJ, Schuster GS, Fairhurst CW. Arresting caries by sealants: results of a clinical study. J Am Dent Assoc 1986;112:1947.

17. Handelman SL, Leverett DH, Espeland
MA, Curzon JA. Clinical radiographic evaluation of sealed carious and sound tooth surfaces. J Am Dent Assoc 1986;113: $751-4$.

18. Handelman SL, Leverett DH, Espeland MA, Curzon JA. Retention of sealants over carious and sound tooth surfaces. Community Dent Oral Epidemiol 1987; 15:1-15.

19. Handelman SL. Therapeutic use of sealants for incipient or early carious lesions in children and young adults. Proc Finn Dent Soc 1991;87:463-75.

20. National Institutes of Health. Consensus development conference statement on dental sealants in the prevention of tooth decay. J Am Dent Assoc 1984;108:233-6.

21. Weerheijm KL, Groen HJ, Bast AJI, Kieft JA, Eijkmam MAJ, van Amerongen WE. Clinically undetected occlusal dentin caries: a radiographic comparison. Caries Res 1992;26:305-9.

22. Weerheijm KL, Gruythuysen RJM, van Amerongen WE. Prevalence of hidden caries. J Dent Child 1992;60:408-12.

23. Weerheijm KL, de Soet JJ, van Amerongen WE, de Graff J. Sealing of occlusal hidden caries lesions: an alternative to curative treatment? J Dent Child 1992;60: 263-8.

24. Dean AG, Dean JA, Burton AH, Dicker RC. Epi Info, version 5: a word processing, database, and statistics program for epidemiology on microcomputers. Stone Mountain, GA: USD, Inc., 1990.

25. SAS Institute Inc. SAS for personal computers, version 6.04. Cary, NC: SAS Institute Inc., 1988

26. Karim MR. Generalized estimating equations macro utility for the SAS system, version 1.25. Baltimore, MD: Department of Biostatistics, Johns Hopkins University, 1988.

27. Rock WP, Evans RIW. A comparative study between a chemically polymerized fissure sealant and a light-cured resin: three-year results. Br Dent ] 1983;155:344 6.

28. Houpt M, Fuks A, Shapira J, Chosack A, Eidelman E. Autopolymerized versus light-polymerized fissure sealant. J Am Dent Assoc 1987;115:55-6.

29. Rock WP, Weatherhill S, Anderson RJ. Retention of three fissure sealant resins. The effects of etching agent and curing method. Br Dent J 1990;168:324-5.

30. Shapira J, Fuks A, Chosack A, Houpt M, Eidelman E. A comparative clinical study of autopolymerized and light-polymerized fissure sealants: five-year results. Pediatr Dent 1990;12:168-9. 